\section{A CASE OF DISSEMINATED HISTOPLASMOSIS}

BY

\section{J. H. O. EARLE, M.D.}

J. H. HIGHMAN, M.B., M.R.C.P.

AND

EUNICE LOCKEY, M.D., B.Sc.

From the Royal Masonic Hospital, London

Histoplasmosis was first described by Darling (1906) in Panama. No further cases were reported until those of Riley and Watson (1926) in Minnesota and of Phelps and Mallory (1926) from Honduras. Since then the disease has become more widely recognized as a clinical entity, the most common presentation being as a pulmonary infection (Sakula, 1953; Murray et al., 1957 ; Edge, 1958). It may, however, present as a granulomatous or ulcerating infection of the upper respiratory tract (Parkes and Burtoff, 1949; Roberts and Forman, 1950; Hutchison, 1952; Poles and Lavertine, 1954) or of tongue or oral cavity (Rawson, et al., 1948 ; Charr, 1953 ; Locket et al., 1953). In other cases enlargement of the lymph nodes may be the only sign, and practically any type of skin lesion may be mimicked (Derry et al., 1942; Miller et al., 1947 ; Symmers, 1956). The primary pulmonary form of the disease has an excellent prognosis, but the localized forms are more serious and the disseminated type is often fatal (Price, 1956). In the disseminated disease a predilection is shown for the reticuloendothelial system--that is, lymph nodes, liver, and spleen-and the adrenals, mucosal surfaces, and skin are also often involved. Brain and bone are rarely affected, however, and the kidney is generally spared (Schwarz, 1956).

Not until the introduction of the histoplasmin skin test (Palmer, 1945) and its use in conjunction with $x$-ray examination of the chest was it realized that a benign subclinical form of the disease also existed. As a result of surveys, it was established that an endemic area exists in the U.S.A. centred on the lowlands around the junctions of the Missouri, Mississippi, and Ohio Rivers. It has been estimated that between 20 and 30 million people in the U.S.A. have at some time been infected with histoplasmosis (Silverman et al., 1955). Though the histoplasmin skin test is not entirely specific and weak reactions may result from cross-reaction with other fungal infections (Mochi and Edwards, 1952; Edwards et al., 1956), the acceptance of strict criteria of positive reactions enables it to be of great value in surveying possible endemic areas. With regard to India and Pakistan, there would appear to be no evidence of histoplasmin skin sensitivity in the surveys so far carried out, provided that definite criteria are observed (Edwards et al., 1956).

The disease is the result of infection by the fungus Histoplasma capsulatum, which exists dimorphically as a hyphal saphrophytic form and an encapsulated yeastlike spore form. Infection from natural sources is probably due to the mycelial phase, and the portal of entry may be the respiratory tract, the alimentary canal, or through the skin. When the disease becomes established, however, it is the yeast-like phase which invades the tissue cells. Fuller descriptions of various aspects of the disease can be found in the Proceedings of the Conference on Histoplasmosis, 1952 (Schwarz, 1956); and in the papers of Parsons and Zarafonetis (1945), Mochi and Edwards (1952), Silverman et al. (1955), Edwards et al. (1956), and Symmers (1956) amongst others.

Symmers (1956), speaking of Britain and discussing all forms of the disease, said: "Histoplasmosis has seldom been recognized in this country, where it is looked upon as an exotic disease and consequently has attracted little attention." Of the 15 cases so far described in Britain, three have been of the disseminated type. A fourth case of this type is presented below.

\section{Case Report}

The patient, a 62-year-old Englishman, was admitted to this hospital on April 6, 1958. He had spent the previous 30 years in India, the first half doing afforestation work centred on Karachi, the second in a Calcutta office. He had been a healthy athletic man, keen on climbing, and a fairly heavy drinker. His main complaints on admission were of a loss of $4 \frac{1}{2}$ stone $(28.6 \mathrm{~kg}$.), anorexia, and great lassitude. He dated his symptoms from an attempt to slim eight months previously (August, 1957), when on medical advice he had taken dexamphetamine sulphate tablets for a few weeks. On ceasing to take them his appetite failed to improve and he felt generally unwell. Two months after this (late September, 1957) he consulted a medical specialist in London, who noted dyspnoea on effort and an odd mental state, in that he described doing things which he had not done. His liver and spleen were just palpable and he had albuminuria. His blood-pressure was $120 / 80$ $\mathrm{mm}$. Hg.

He returned to India and in December, 1957, consulted a surgeon about an ulcer on his tongue. In February, 1958, this was excised and at the same time a small mass of granulation tissue, which had appeared around the anus, was also removed. Both sites healed well. Histologically the tongue lesion was described as a granular-cell myoblastoma and the anal lesion as non-specific granulation tissue. His general health continued to deteriorate, the loss of weight becoming ever more rapid and the lethargy and mental state giving rise to great anxiety for his sanity.

He returned to London in April and was admitted to hospital. At this time he was so drowsy that it was difficult to obtain a history. He had slight fever and appeared anaemic, but there was no abnormal pigmentation of his skin or mucous membranes. He had obviously lost weight, but was by no means wasted (weight $11 \frac{1}{2}$ stone ; $73 \mathrm{~kg}$.). A healed scar was present on the dorsum of his tongue. Both liver and spleen were just palpable, but otherwise no abnormal physical signs were elicited. His blood-pressure was $120 / 80 \mathrm{~mm}$. $\mathrm{Hg}$.

Because of the anorexia and loss of weight, carcinoma of the stomach was suspected, but a barium-meal examination showed no abnormality of his gastro-intestinal tract apart from some colonic diverticulosis. A chest $x$-ray examination made at the same time revealed no abnormality of his heart, aorta, or lungs.

His haemoglobin concentration was 8.8 g./100 ml. $(60 \%)$ and the white-cell count $3,000 /$ c.mm. (neutrophils $51 \%$, lymphocytes $44 \%$, monocytes $2 \%$, eosinophils $3 \%$ ). During the next nine weeks the haemoglobin concentration only once exceeded $10.4 \mathrm{~g} . / 100 \mathrm{ml}$., and his anaemia was always of the normochromic normocytic type. The average of the nine estimations done was $9.6 \mathrm{~g} . / 100 \mathrm{ml}$. The total whitecell count was usually low $(3,000-4,000 / \mathrm{c} . \mathrm{mm}$.), only once reaching $8,000 /$ c.mm., and apart from the first two counts always showed a neutrophil preponderance (more than $80 \%$ ). 
The erythrocyte sedimentation rate was always raised, the highest reading being $56 \mathrm{~mm}$. in the first hour and $95 \mathrm{~mm}$. in the second (Westergren). Sternal marrow taken two weeks after admission showed no abnormality apart from some increase in the number of eosinophil myelocytes.

The empirical tests of liver function were all abnormal at the time of admission (thymol turbidity 5 units, thymol flocculation $2+$, serum colloidal gold $2+$, zinc sulphate turbidity 12 units, ammonium sulphate turbidity 4 units). This was thought to be probably connected with his alcohol consumption. The total serum protein concentration was $6.2 \mathrm{~g} . / 100 \mathrm{ml}$, , the $\mathrm{A} / \mathrm{G}$ ratio being 1.48 .

Clinically his condition remained unchanged during the first week, the low-grade fever continuing with occasional spikes of temperature up to $100.8^{\circ} \mathrm{F}$. $\left(38.2^{\circ} \mathrm{C}\right.$.). One week after admission, however, his condition suddenly deteriorated and he became more drowsy, was confused, had hiccups, exhibited muscle twitchings, and had an unpleasant oral fetor. His blood urea was found at this

$100 \mathrm{ml}$. on the tenth day. The serum sodium and chloride levels remained normal. The daily urine output at this time continued to be good, but the urea concentration was only $0.95 \mathrm{~g} . / 100 \mathrm{ml}$. The chloride concentration was 38 $\mathrm{mEq} / 1$. or $2.2 \mathrm{~g}$. / 1 . as sodium chloride.

His general condition did not improve on this regime, and by now some more generalized disease process, such as disseminated lupus erythematosus, was being postulated in an attempt to explain the hepatosplenomegaly, abnormal mental state, leucopenia, raised erythrocyte sedimentation rate, and abnormal biochemical tests. No L.E. cells could be demonstrated in his circulating blood, but, in view of his critical state, it was decided to start steroid therapy. $100 \mathrm{mg}$. of hydrocortisone was therefore added to the intravenous infusion for two days, followed by oral prednisone in a dose of $10 \mathrm{mg}$. eight-hourly.

On this regime there was a dramatic clinical improvement, which was maintained for the next three weeks. He became mentally clear, alert, and communicative. The liver and spleen ceased to be palpable, and the empirical liver-function tests became negative and remained so. The prednisone induced a diuresis-urine volumes around 3 litres a day being produced. His blood urea fell rapidly from its level of $234 \mathrm{mg} . / 100 \mathrm{ml}$. at the start of steroid therapy to $86 \mathrm{mg}$./ $100 \mathrm{ml}$. a fortnight later, before starting to rise again. The serum sodium and chloride levels were also reduced to their lowest values, being $130 \mathrm{mEq} / 1$. and $100 \mathrm{mEq} / 1$. respectively at this stage.

Though the urea content of the urine was still low at $0.58 \mathrm{~g} . / 100$ $\mathrm{ml}$. and the sodium and chloride contents slightly low at $52 \mathrm{mEq} / 1$. and $55 \mathrm{mEq} / 1$. respectively, it was felt that the diuresis was sufficient to account for these values.

It was difficult to explain, except by postulating increasing cell damage, the serum potassium level, which steadily rose from 4.7 to $7.3 \mathrm{mEq} / \mathrm{l}$. after three weeks of steroid therapy, despite a good

time to be $165 \mathrm{mg} . / 100 \mathrm{ml}$., serum sodium $140 \mathrm{mEq} / 1$, potassium $5.9 \mathrm{mEq} / 1$., chloride $107 \mathrm{mEq} / \mathrm{l}$., and alkali reserve $20 \mathrm{mEq} / \mathrm{l}$. (Fig. 1). He had had slight proteinuria (about $50 \mathrm{mg} . / 100 \mathrm{ml}$.) since admission, and a urine specific gravity greater than 1007 had never been obtained. No casts, cells, or organisms were found in the urine at this time, and the daily output was at least a litre. The $p \mathrm{H}$ was always on the acid side of neutrality. This combination of high serum urea and potassium, with a urine of reasonable volume but low specific gravity and containing albumin, suggested a renal lesion, and since his blood urea five months previously was $26 \mathrm{mg} . / 100 \mathrm{ml}$. it seemed that such a lesion must have been of recent onset or sudden deterioration.

As the symptoms, clinical state, and laboratory findings were compatible with either renal or hepatic failure, he was put on a routine of intravenous $10 \%$ dextrose together with a diet very low in protein, and $0.25 \mathrm{~g}$. of tetracycline six-hourly by mouth. This latter was discontinued after five days because of diarrhoea and anal excoriation. The temperature settled at this time, and from then on was subnormal, frequently being as low as $95-96^{\circ} \mathrm{F}$. $\left(35-35.6^{\circ} \mathrm{C}.\right)$. The intravenous therapy was continued for 10 days, and during this time the serum potassium level fell to $4.7 \mathrm{mEq} / 1$., presumably because of a shift from the extracellular to the intracellular fluids. The blood urea level, however, rose ever higher to a maximum of $234 \mathrm{mg}$./ urine potassium content of $27 \mathrm{mEq} / \mathrm{l}$. An attempt was made to check this rise, by removing foods high in potassium from the diet and later by giving "resonium-A," 15 g. t.d.s. This controlled the serum potassium in the $5 \mathrm{mEq} / 1$. region while it was given. The blood urea continued to rise, finally reaching $288 \mathrm{mg}$. $/ 100 \mathrm{ml}$.

On two occasions he had a trace of blood in the urine, and on May 16 (three weeks before death and a month after starting steroid therapy) he had the first of several attacks of frank haematuria. Because of the serum urea concentration an intravenous pyelogram was never feasible. Cystoscopy was performed, but no abnormality was found in the bladder, and ureteric catheters could not be passed.

Haematuria became persistent and gross, and despite blood transfusion he gradually went downhill and died on June 6 , nine weeks after admission. In the last week of his life prednisone dosage had been reduced to $5 \mathrm{mg}$. t.d.s. and the resonium-A discontinued. On the day of death the serum potassium was $12.6 \mathrm{mEq} / 1$. and the serum urea $288 \mathrm{mg}$. $/ 100 \mathrm{ml}$.

\section{Necropsy Findings}

There was no increased pigmentation of the skin, nipples, anus, or oral cavity. The brain $(1,280 \mathrm{~g}$.) was macroscopically normal. On the dorsum of the tongue there was 
a recurrence of the ulcer $1 \mathrm{~cm}$. in diameter. The gastrointestinal tract was normal and there was no recurrence of the anal granuloma. There were no lesions of the lungs or bronchi. The heart $(395 \mathrm{~g}$.) had been arrested in systole (interesting in view of the high serum potassium level which is said to cause arrest in diastole). There was moderate hypertrophy of the left ventricular myocardium. The liver $(2,495 \mathrm{~g}$.) was enlarged and finely nodular. The cut surface showed the appearances of a multilobular type of cirrhosis

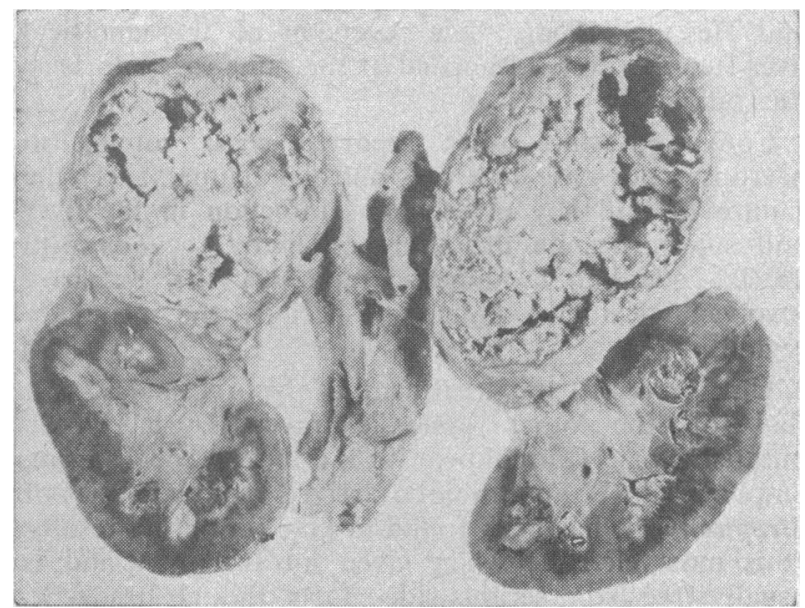

Fio. 2.-Kidneys and adrenals, showing gross adrenal destruction and extensive lesions of renal medulla.

with dilatation of some of the bile-ducts, which appeared occasionally as small cysts. The spleen $(760$ g.) was enlarged and firm, with a normal architecture.

The adrenals were replaced by large tumour-like swellings (Fig. 2); that on the right was roughly spherical $(8-9 \mathrm{~cm}$. in diameter); that on the left more oblong ( 13 by 8 by $7 \mathrm{~cm}$.). The cut surface of each showed considerable amounts of yellowish necrotic material within fairly thin fibrous capsules. There was an occasional thickening of the capsule by firm white tissue measuring

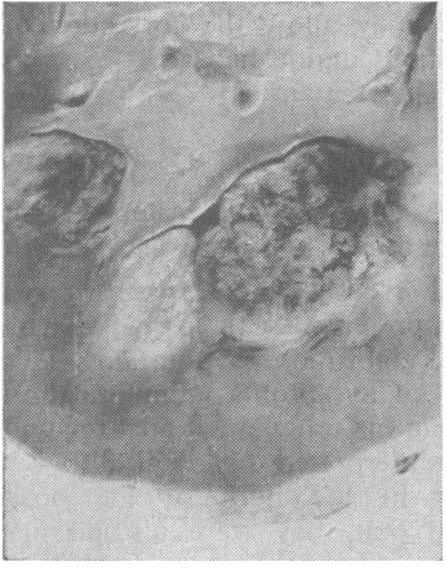

Fio. 3.-Kidney, showing typical lesions of renal medulla. up to $3 \mathrm{~cm}$.

The kidneys were of normal size and contour. Cut surface revealed, confined to the medullary region, several circumscribed, almost spherical lesions greyish-white in colour, with streaks of haemorrhage and areas of necrosis (Figs. 2 and 3). Small miliary foci could also be seen and there was a streaky effect in the line of the medullary rays.

The most likely diagnosis appeared to be tuberculosis, but

the lesions did not show true caseation, and aroused sufficient curiosity for a frozen section to be done, as a result of which the diagnosis of histoplasmosis was established.

It was now realized that the ulcer of the tongue removed in India could have been due to histoplasmosis. The original blocks of the tongue ulcer and anal lesion were obtained, and this fact was confirmed.
Serum taken on the day of death and refrigerated was sent to Dr. R. W. Riddell for complement-fixation tests, but proved anti-complementary. The blood clot was cultured in various suitable media, but no growth was obtained.

\section{Histology}

The characteristic picture in the sections of the granuloma of the tongue and anal region, and in the lesions in the adrenal and kidney, was of great accumulations of macrophages containing vast numbers of intracellular histoplasmas. None of the macrophages was multinucleated, though an occasional binucleate form was found.

The histoplasmas (Fig. 4) were so abundant that they were easily visible in haematoxylin-and-eosin-stained sections at low magnification. They were of relatively uniform size, oval in shape (about 4 by $2 \mu$ ), with a double contour external wall. They were best demonstrated by the periodic-acid/Schiff technique, when a central granular pink-staining chromatin mass could be identified, with a clear zone between it and the external wall. Most of the organisms were birefringent. They were not so clearly demonstrated by Gridley's stain as by P.A.S. These appearances were exactly similar to previous descriptions of histoplasmas, as was their peculiar confinement to macrophages. The organisms were larger than those of leishmania, and, unlike them, had caused considerable cell destruction.

In the adrenal tumours the heavily parasitized macrophages were collected together in islands surrounded by large areas of necrosis, in which were vast numbers of free histoplasmas. These were not as conspicuous as their intracellular counterparts, many staining poorly and appearing

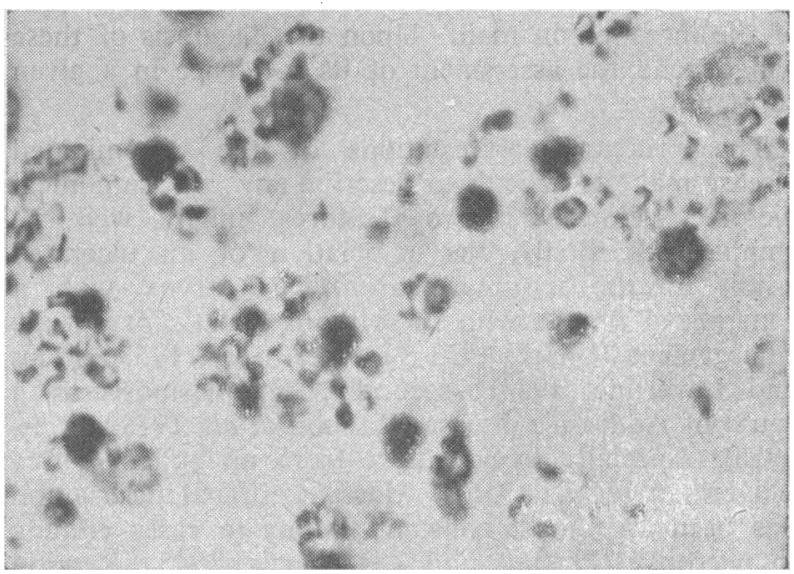

Fio. 4.-Typical microscopical appearance of macrophages with intracellular histoplasmas. $(\times 1,600)$

to be disintegrating. Only an occasional microscopic focus of surviving adrenal tissue was found.

The large lesions in the renal medulla were of a similar nature and had caused much destruction of tissue. The miliary lesions were some 2-3 $\mathrm{mm}$. in diameter and consisted of an outer zone of macrophages and histiocytes surrounding an area of early necrosis, in which a few polymorphonuclear cells could be identified. The macrophages in these lesions contained very few histoplasmas, and the histiocytes only an occasional single organism.

No histoplasmas were found in the liver or spleen despite the examination of numerous sections using special staining techniques. In the liver the changes of a multilobular type of cirrhosis were confirmed, and it was presumed that this had an alcoholic aetiology and was not related to histoplasmosis. 


\section{Discussion}

The possible association of histoplasmosis with residence in India seems worthy of reiteration. In two of the three fatal cases previously reported in Britain, also in Hutchison's laryngeal case, the patients had all lived there for varying periods, and it would seem that it was in India that the present patient acquired his infection. Though only one report of a case actually diagnosed in India has been found (Panja and Sen, 1954) the possibility of histoplasmosis, both in Indian patients and in those who have lived in that country, should be considered when appropriate.

Diagnosis is best established by culture of the organisms from biopsy material, blood, bone-marrow, sputum, or gastric washings, and is preferable to merely seeing them microscopically in these materials (Silverman et al., 1955). The histoplasmin skin test is probably clinically analogous to the Mantoux test in tuberculosis. Serological methods include various complement-fixation and agglutination tests, and as these become positive at different stages of the disease (Campbell, 1958) they are best employed altogether at any one time. Biopsy has been said to precipitate dissemination of the disease, but Symmers (1956) believes that this danger may be exaggerated. His three patients were still alive and well, three years after biopsy, without any evidence of dissemination of the disease (Symmers, 1959, personal communication).

It is not within the scope of this paper to discuss in detail the localized lesions or pulmonary forms, though these undoubtedly form by far the major part of the infection in man. Upon the diagnosis of these will depend the assessment of its incidence in a given community.

The protean manifestations of the disseminated disease make it difficult to describe any concise clinical picture. However, two features might well be emphasized: firstly, the association of an ulcerated lesion of the mouth, pharynx, or larynx with a generalized illness, with or without hepatic or splenic enlargement (Charr, 1953 ; Locket et al., 1953 ; Poles and Lavertine, 1954); secondly, histoplasmosis as a cause of Addison's disease (Rawson et al., 1948 ; Price, 1956), especially in a patient from an endemic area (Silverman et al., 1955). Massive adrenal destruction has been an almost constant finding in cases coming to necropsy (Parsons and Zarafonetis, 1945; Rawson et al., 1948), and, though some equivocal signs which could be associated with adrenal insufficiency have commonly been present, a full Addisonian state is rare, manifestations of disease elsewhere usually being dominant, as in the present case. With regard to the first of these points, had the importance of the tongue ulcer been realized, the diagnosis might have been established in life. Regarding the second, the difficulty in diagnosing the Addisonian state has been demonstrated. The normal sodium and chloride levels in the serum and urine, together with the absence of clinical evidence of adrenal insufficiency, militated against the diagnosis of Addison's disease - the high serum urea and potassium concentrations and the low urine urea concentrations being ascribed to a renal lesion, this supposition being borne out by the constant low specific gravity of the urine and the presence of albuminuria and haematuria.
The mental condition of the patient is not likely to have been the direct result of the infection, as after death no abnormality was discovered in the nervous system such as the granulomatous basal meningitis reported in a disorientated patient by Sprofkin et al. (1955). However, it may well have been related to his presumably alcoholic cirrhosis, the improvement resulting from prednisone being analogous to the temporary improvement reported in some cases of hepatic coma (Webster and Davidson, 1957; Pessar and Hessing, 1958). The reversion of the empirical liver-function tests to normal at this time seems to bear this out.

Compared with other reported cases coming to necropsy, our case had two unusual features: (1) the failure to find any evidence of infection in the liver and spleen despite the study of many sections with special staining techniques; and (2) the extensive involvement of the kidneys, especially the medullary region.

Until recently the treatment of histoplasmosis, like that of . the other systemic mycoses, has been unsatisfactory (Furcolow, 1958); but a new agent, amphotericin B, an antibiotic derived from a species of Streptomyces, has been found to give promising results. It is most effective when given intravenously and is usually free from serious side-effects, though headache, febrile reactions, local phlebitis, and temporary renal impairment have been reported (Appelbaum and Shtokalko, 1957 ; Rubin et al., 1957 ; Biddle and Koenig, 1958; FitzPatrick et al., 1958; Greendyke and Kaltreider, 1959).

When there is evidence of adrenal failure the administration of cortisone is hazardous, as it may accelerate the disease process despite an initial period of apparent improvement (Silverman et al., 1955). This fact may be the explanation of the paradoxical rise of serum potassium in our case when the serum urea was falling during the administration of prednisone. The concurrent administration of a potent antifungal drug with the adrenal steroid may allow the correction of the Addisonian state without undue hazard.

\section{Summary}

The fourth case of disseminated histoplasmosis reported in Britain is described.

The patient, who had lived in India for 30 years, was a man aged 62 who presented with loss of weight, anorexia, and lassitude of eight months' duration. Two months after the onset of symptoms, granulomatous lesions were removed from his tongue and anal regions. These were at first misinterpreted histologically, but review of the sections in the light of the postmortem findings showed that they were histoplasmic granulomas.

Interesting features of the electrolyte disturbances are discussed.

Necropsy revealed gross destruction of the adrenals and considerable involvement of the kidneys due to Histoplasma capsulatum.

We thank Lord Evans, under whose care the patient was admitted, for permission to publish this case. Our thanks are also due to Professor W. St. C. Symmers for much helpful criticism and advice in the preparation of 
this paper, and to Dr. R. W. Riddell for the complementfixation tests. REFERENCES

Appelbaum, E., and Shtokalko, S. (1957). Ann. intern. Med., 47, 346 .

Biddle, A., and Koenig, H. (1958). A.M.A. Arch. intern. Med., 102,801

Campbell, C. C. (1958). In Fungous Diseases and Their Treatment, edited by R. W. Riddell and G. T. Stewart, p. 142. Butterworth, London.

Charr, R. (1953). Amer. Rev. Tuberc., 67, 376.

Darling, S. T. (1906). J. Amer. med. Ass., 46, 1283.

Derry, D. C. L., Card, W. I., Wilson, R., and Duncan, J. T. (1942). Lancet, 1, 224.

Edge, J. R. (1958). Brit. J. Tuberc., 52, 45.

Edwards, P. Q., Geser, A. G., Kjølbye, E. H., Meijer, J., and Christensen, O. W. (1956). Amer. J. trop. Med. Hyg., 5, 224.

FitzPatrick, M. J., Rubin, H., and Poser, C. M. (1958). Ann. intern. Med. 49, 249.

Furcolow, M. L. (1958). Fungous Diseases and Their Treatment, edited by R. W. Riddell and G. T. Stewart, p. 241. Butterworth, London.

Greendyke, R. M., and Kaltreider, N. L. (1959). Amer. J. Med. 26, 135.

Hutchison, H. E. (1952). J. Path. Bact., 64, 309.

Locket, S., Atkinson, E. A., Grieve, W. S. M., and Bridson, E. (1953). Brit. med. J., 2, 857.

Miller, H. E., Keddie, F. M., Johnstone, H. G., and Bostick, W. L. (1947). Arch. Derm. Syph. (Chicago), 56, 715.

Mochi, A., and Edwards, P. Q. (1952). Bull. Wld Hlth Org., 5, 259.

Murray, J. F., Lurie, H. I., Kaye, J., Komins, C., Borok, R., and Way, M.' (1957). S. Afr. med. J., 31, 245.

Palmer, C. E. (1945). Publ. Hlth Rep. (Wash.), 60, 513.

Panja, G., and Sen, S. (1954). J. Indian med. Ass., 23, 257.

Parkes, M., and Burtoff, S. (1949). Med. Ann. D.C., 18, 641.

Parsons, R. J., and Zarafonetis, C. J. D. (1945). Arch. intern. Med., 75, 1 .

Pessar, T., and Hessing, J. W. (1958). Ann. intern. Med., 48, 1254.

Phelps, B. M., and Mallory, F. B. (1926). Rep. un. Fruit Co. med. Dep. N.Y., 15, 115 .

Poles, F. C., and Lavertine, J. D. O'D (1954). Thorax, 9, 233.

Price, F. W. (1956). Price's Textbook of the Practice of Medicine, 9 th ed., edited by D. Hunter. Oxford Univ. Press, London.

Rawson, A. J., Collins, L. H., jun., and Grant, J. L. (1948), Amer. J. med. Sci., 215, 363 .

Riley, W. A., and Watson, C. J. (1926). Amer. J. trop. Med., 6, 271

Roberts, S. E., and Forman, F. S. (1950). Ann. Otol. (St. Louis), $59,809$.

Rubin, H., Lehan, P. H., and Furcolow, M. L. (1957). New Engl. J. Med., 257, 599.

Sakula, A. (1953). Tubercle (Lond.), 34, 18.

Schwarz, J. (1956). Publ. Hlth Monogr., No. 39. p. 12.

Silverman, F N., Schwarz, J., Lahey, M. E., and Carson, R. P. (1955). Amer. J. Med., 19, 410.

Sprofkin, B. E., Shapiro, J. L., and Lux, J. J. (1955). J. Neuropath., 14, 288.

Symmers, W. St. C. (1956). Brit. med. J., 2, 786, 790.

Webster, L. T., and Davidson, C. S. (1957). Gastroenterology, 33, 225.

In 1959 the Society of Public Health Educators in America published three additional monographs in their series, Numbers 4, 5, and 6. Number 4, by Dr. W. Griffiths (University of California), is "Health Workers' Attitudes toward Community Development Programs"; in Number 5, Dr. Cora DuBois (Harvard University and Radcliffe College) reconciles the theories of anthropologists, sociologists, and psychologists as they relate to socio-cultural change. Also in Number 5 is an appraisal of operational research in health education by Dr. K. D. Benne (Boston University). Number 6 contains three articles: "Motivation-Some Basic Psychological Issues," by Dr. Richard S. Lazarus (University of California); "Motivation in Small Groups," by Dr. Edmund H. Volkart (Stanford University); and "Power and Participation in the Local Community," by Dr. William Kornhauser (University of California). Further details are available from the Society of Public Health Educators, Office of the Monograph Committee, 121, East 11th Street, Oakland, California, U.S.A.

\section{STUDIES ON THE HAEMOGLOBIN OF NEWBORN NIGERIANS}

\author{
BY
}

\section{R. G. HENDRICKSE, M.D., M.R.C.P.Ed.}

A. E. BOYO,* M.A., M.B., B.Chir., M.R.C.S.

P. A. FITZGERALD, M.B., Ch.B., M.R.C.P., D.C.H.

$$
\text { AND }
$$

S. RANSOME KUTI, B.Sc.

From the Children's Department, University College Hospital, Ibadan, Nigeria

In studies of diseases caused by inheritance of the abnormal haemoglobins, in particular haemoglobin $\mathrm{S}$, the presence of foetal haemoglobin in the erythrocytes during the first few months of life interferes with early determination of the haemoglobin genotype of individuals (using the standard techniques as present in general use). As a result sickle-cell anaemia and its genetic variants have not been detected at birth or during the first three months of life, and consequently this gap in our knowledge of the natural history of these diseases remains to be filled. It has also been impracticable to include the neonatal period in investigations on the population dynamics of the sicklecell gene. It is not inconceivable that factors which operate during this period might lie behind some of the riddles presented by sickling frequencies in populations.

In March, 1958, it was decided to investigate the haemoglobins of babies at birth and to follow up these cases for six months in order to get an idea of the changing pattern of the haemoglobin content of the erythrocytes. We hoped that the pattern of results of the standard tests employed might point a way to earlier definitive diagnosis of diseases caused by the abnormal haemoglobins.

The object of this communication is to present the results of some of our investigations, in particular our findings on filter-paper electrophoresis of the haemoglobin, which in a number of cases yielded unexpected and unusual results.

\section{Material and Methods}

The subjects in this investigation were 100 babies born at University College Hospital, Ibadan. The only criterion for inclusion was that a sample of cord blood was obtained at delivery. Subsequently, samples of blood were collected monthly at the post-natal clinic. Unfortunately, a large proportion of cases defaulted

TABLE I.-Number of Cases Attending Monthly Follow-up

\begin{tabular}{c|c|c|c|c|c}
\hline & Birth & 1 Month & 2 Months & 3 Months & 4 Months \\
\hline No. of cases .. & 100 & 50 & 29 & 18 & 4 \\
\hline
\end{tabular}

from follow-up, and in many cases our investigations are incomplete. Table I shows the follow-up achieved.

(1) Sickling tests were done using freshly prepared $2 \%$ sodium metabisulphite. (2) Foetal haemoglobin

* Research Associate, supported in part by the Colonial Medical Research Council, Anthropology Department, Oxford, and University College, Ibadan. 